\title{
Application of remote sensing and GIS in the study of environmental sensitivity to desertification: a case study in Basrah Province, southern part of Iraq
}

\author{
A. S. Hadeel $\cdot$ Mushtak T. Jabbar $\cdot$ Xiaoling Chen
}

Received: 2 September 2009 / Accepted: 31 May 2010/Published online: 19 June 2010

(C) The Author(s) 2010. This article is published with open access at Springerlink.com

\begin{abstract}
This research utilizes the integrated remote sensing and geographic information systems (GIS) in the southern part of Iraq (Basrah Province was taken as a case) to assess the environmentally sensitivity area to desertification. The thematic layers of soil, vegetation, climate, and extent of sand movement are the main data required for estimating the desertification sensitivity index. These layers were extracted and manipulated from the available topographic map data, geologic map, satellite image (TM in 1990 and ETM+ in 2003), and field survey data analyses. Spatial analyst function in ArcGIS 9.3 software was used for matching the thematic layers and assessing the desertification index. The obtained data on change detection reveal that the area of active sand movement has increased from $4,118.3$ to $4,558.1 \mathrm{~km}^{2}$, and the highly sensitive areas for sandy desertification are located in the western-southern parts of Basrah Province, representing $61.9 \%$ of the area belonging to class 5 . The rest of the southern parts of the study location exhibit moderately sensitive areas for desertification, representing $18.9 \%$ of the total area belonging to class 4 . The northern parts of the
\end{abstract}

A. S. Hadeel $\cdot$ M. T. Jabbar $(\bowtie) \cdot$ X. Chen

State Key Laboratory of Information Engineering in Surveying, Mapping and Remote Sensing (LIESMARS), Wuhan University, No. 129, Luoyu Rd, Wuchang,

Wuhan, Hubei Province 430079, People's Republic of China

e-mail: mushtak1967@yahoo.com

e-mail: mushtak208@hotmail.com

\section{T. Jabbar}

Department of Soil and Water, College of Agriculture, University of Basrah,

Basra, Iraq

\section{Chen}

Key Laboratory of Poyang Lake Wetland and Watershed Research (Ministry of Education), Jiangxi Normal University,

Nanchang, China study location are characterized by a very low and low sensitivity for desertification, representing $8.5 \%$ and $10.7 \%$ of the total area, respectively. It is recommended that there is a need to establish a professional arid environment center, which can be coordinated with government sectors and different universities in southern part of Iraq to solve various environmental problems.

Keywords Degradation ESA · Remote sensing · GIS . Spatial analyst · Iraq

\section{Introduction}

Desertification is defined in the first art of the convention to combat desertification as "land degradation in arid, semiarid and dry sub-humid areas resulting from climatic variations and human activities" (Thomas 1997; Kassas 1995; Binns 1990). Its consequences include a set of important processes which are active in arid and semi-arid environment, where water is the main limiting factor of land use performance in such ecosystem (Collado et al. 2002; Zha and Gao 1997). Sandy desertification is one of the most serious ecological problems in the world (Abahussain et al. 2002; Al Dousari et al. 2000). Iraq like many other countries in the arid and semi-arid region is exposed to desertification problems, especially in the middle and southern parts of Iraq, which are estimated to be about one million hectares (UNEP 2001; Jabbar 2001). For assessment of desertification processes, various models have been proposed. The Mediterranean Desertification and Land Use (MEDALUS) is the latest model, which later in 1999 was named as environmentally sensitive areas (ESAs) by Kosmas et al. (1999). The use of the MEDALUS model based on ESAs index (Basso et al. 2000) was carried 
out to determine the situation and tendency of desertification in Sicily, Italy. In MEDALUS, a distinction has been made between degradation processes in European Mediterranean environments and the more arid areas. Physical loss of soil by water erosion and associated loss of soil nutrient status are identified as the dominant problems in the European Mediterranean region. However, wind erosion and salinization problems are most often in the arid Mediterranean areas (Koulouri and Giourge 2007; Basso et al. 1998; Vandekerckhove et al. 1998). ESAs to desertification around the Mediterranean region exhibit different sensitivity status to desertification for various reasons. For example, there are areas presenting high sensitivity to low rainfall and extreme events due to low vegetation cover, low resistance of vegetation to drought, steep slopes, and highly erodable parent material (Ferrara et al. 1999). Land degradation processes involve two interlocking, complex systems: the natural ecosystem and the human social system (World Meteorological Organization 2005). Natural forces, through periodic stresses of extreme and persistent climatic events, human use, and abuse of sensitive and vulnerable dry land ecosystems often act in unison, creating feedback processes. Interactions between the two systems determine the severity of the degradation process. Inclusion of climate, vegetation, and land use into desertification assessment is reviewed by Jabbar and Xiaoling (2006). Desertification indicators are those which indicate the potential risk of desertification while there is still time and scope for remedial action. Regional indicators should be based on available international source materials, including remotely sensed images, topographic map data, climate, soil, and geologic data
(Nicholson et al. 1998; Thornes 1995). At the scale $1: 25,000$, the impact of socio-economic drivers is expressed mainly through pattern of land use. Each regional indicator or group of associated indicators should be focused on a single desertification process. The various types of ESAs to desertification can be distinguished and mapped by using certain key indicators for assessing land capability to withstand further degradation or land suitability for supporting specific types of land use. The key indicators for defining ESAs to desertification, which can be used at a regional or national level, can be divided into four broad categories defining the qualities of soil, climate, vegetation, and land management (Kosmas et al. 1999). This approach includes parameters, which can easily be found in existing soil, vegetation, and climate reports. This study aims at using spatial analyses in geographic information systems (GIS) to assess and map the environmental sensitivity for sandy desertification in the southern part of Iraq.

\section{Materials and methods}

\section{Materials}

In order to study the development of desertification, the AlBasrah Province has been selected as a study area. Geographically, the province is situated in the southern part of Iraq at the northwestern corner of the Arabian Gulf, within the longitude $46^{\circ} 60^{\prime}$ to $48^{\circ} 60^{\prime} \mathrm{E}$ and from the latitude $29^{\circ} 13^{\prime}$ to $31^{\circ} 29^{\prime} \mathrm{N}$, with a total area of $19,070 \mathrm{~km}^{2}$ (Fig. 1). Geomorphologically, the soil of the study location is considered as flat
Fig. 1 General location of the study area in the southern part of Iraq

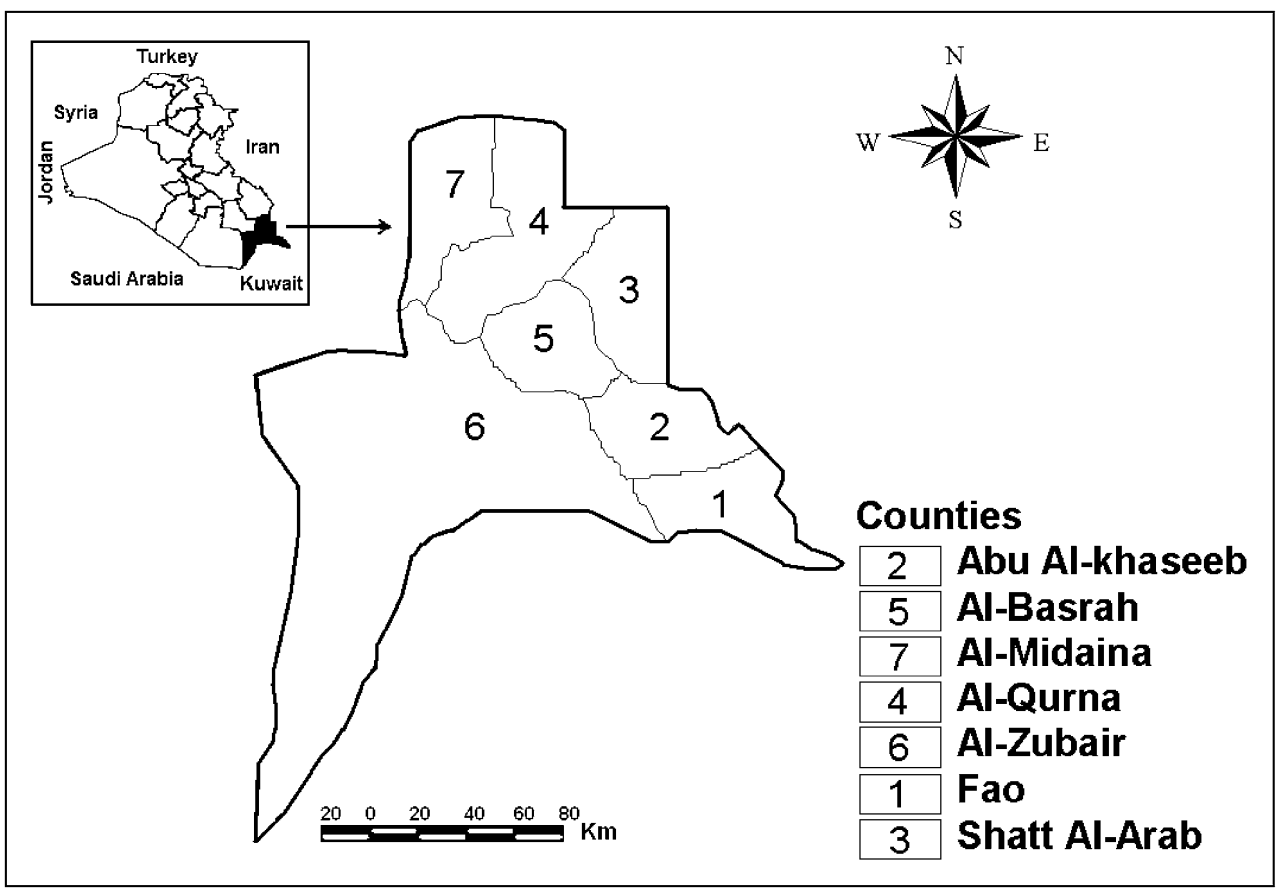


sedimentary soil and it is located on the downwind side of the high deflational area of the Mesopotamian flood plain in southern Iraq. During summer, the prevailing northwesterly wind, which reaches a maximum of $30 \mathrm{~ms}^{-1}$ in June, transport sands and finer particles from this flood plain towards Basrah. Climatically, like most parts of the Arabian Peninsula, a desert-type environment with scanty rainfall and hot dry weather characterizes the climate of Basrah. Summer is very hot, especially in July and August, with mean temperatures of $37.4^{\circ} \mathrm{C}$ and maximum mean temperatures of $45^{\circ} \mathrm{C}$. The average evaporation exceeds $2450 \mathrm{~mm}$ /year with average annual rainfall less than $100 \mathrm{~mm} /$ year. In the western parts of Basrah Province, the scarcity and irregularity of rainfall, the availability of sand supply areas, and the prevalence of strong northwesterly winds significantly influence the stability and productivity of the desert ecosystem. In more than two decades, the vulnerable terrestrial environment of Al-Basrah Province has been subjected to intensive pressure from urbanization, overutilization of resources, and war activities. Several indicators of land degradation have been recognized in Al-Basrah Province (Jabbar 2001).

The thematic layers of soil quality index (SQI), vegetation quality index (VQI), climate quality index (CQI), and extent of sand movement (crust index (CI)) are the main data required for estimating the desertification sensitivity index (DSI). These layers were extracted and manipulated from the available topographic data, geologic map, satellite image (two images of Landsat satellite TM and ETM+ pertaining to $165 / 39,166 / 38,166 / 39$, and 166/40 path and row acquired for a period of 13 years (1990-2003)), and field survey data analyses. For processing the satellite data and other needed information, various software such as, ERDAS ver. 9.2, ArcGIS ver. 9.3, etc. were used.

\section{Methods}

Two interaction goals were followed in this study. In the first stage, remote sensing techniques were used in the evaluation of surface changes, determination of the type of topsoil grain size index, and extent of sand movement. In the next stage, the area was evaluated for sensitivity to desertification by using the desertification method (ESAs) and GIS tools (Fig. 2).

\section{Field work and laboratory studies}

Soil samples from the location study in Basrah Province, southern part of Iraq were collected during the study period from 13 typical soils of each county polygon with their GPS locations. They were used to see the position of spatial sand dunes (dunes height, length, and slope ratio) in the study area. The dry sieving analysis has been done to obtain common grain sizes. Four randomized samples were taken from each typical point by using a manual tool to pluck out the aggregates without agitating it from the soil surface layer and then placed in cans and taken to the laboratory for analysis. The vegetation density spatial data were digitized from the topographic maps of the study areas by using ArcGIS version 9.3, and then vegetation density attribute
Fig. 2 Flow chart of mapping desertification sensitivity index $(D S I)$

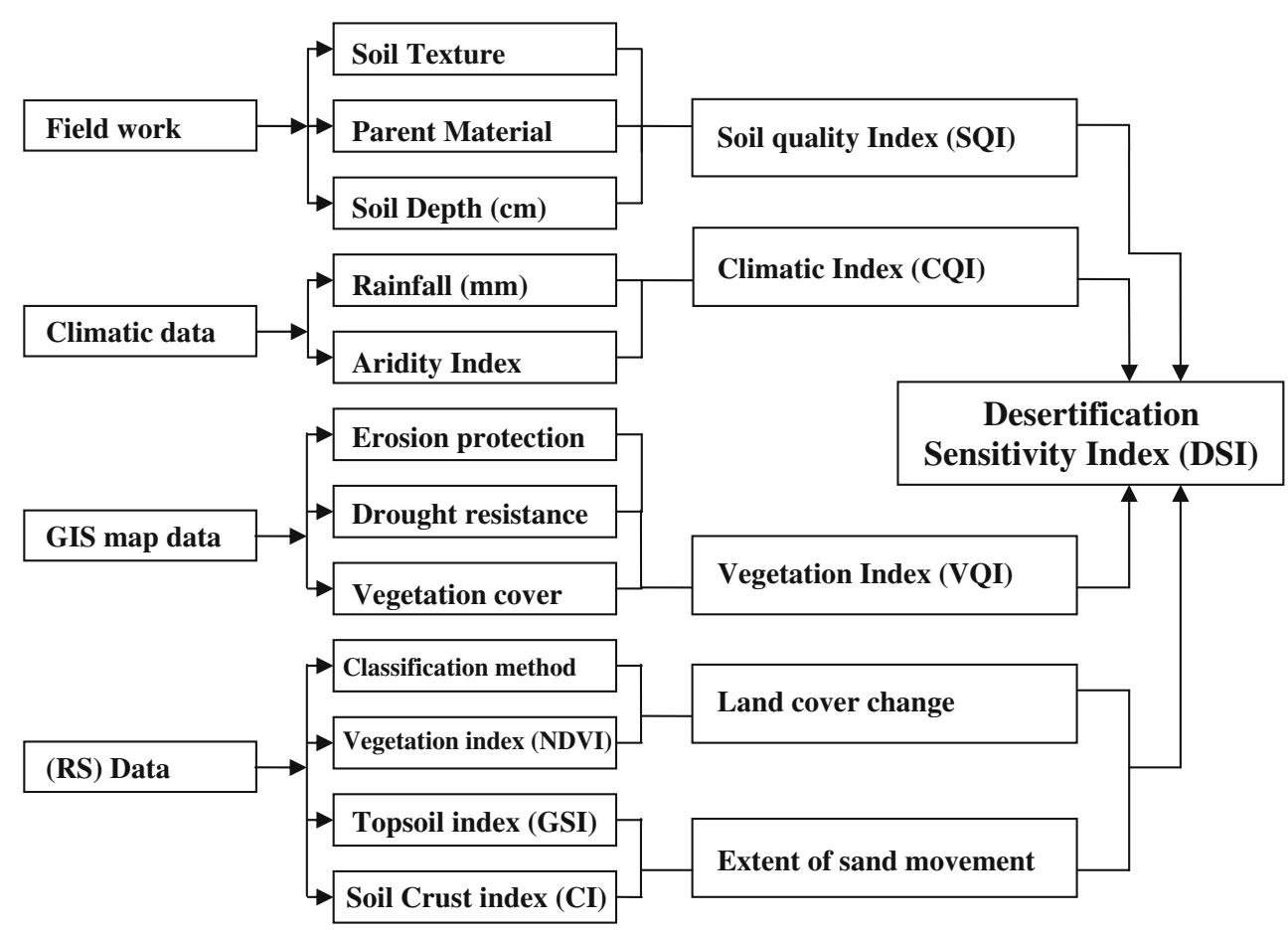


data were edited and added to the study databases. The polygons and their attributes were connected with a uniform code. Selected physical and chemical properties of the soils were listed in Table 1, and these properties were measured according to the procedures of Black (1965) and USDA (2004).

\section{Remote sensing techniques}

Satellite data and preprocessing of image Landsat TM of 1990 and Landsat ETM of 2003 were used for the environmental sensitivity area to desertification. The ETM and TM sensor consists of detectors, which produce signals proportional to the average amount of light reflected from an area of $28.5 \times 28.5 \mathrm{~m}$, which correlates to the geometrical resolution of a Landsat TM sensor. Random distortion needs to be corrected by the analyst through the selection of a sufficient number of ground control points with correct coordinates.

Through the use of a rectification algorithm image and/ or vector, the column and row coordinates of the image can be fitted to the Geodetic Datum WGS84 and map projection NUTM38 coordinate system built into the vector using the linear method.

The resampling method chosen was nearest-neighbor, which preserved original reflectance value. Fifty ground control points were chosen on the images, primarily on the clearly visible river. The points were spread quite evenly throughout the image, allowing for good control. Image software allowed for easy zooming to assist in point selection. The points were registered in the header file of the image for later rectification. Once all ground control points were compiled, error checking was used to gauge the efficiency of the points used. The RMS errors for a linear method of rectification were examined with varying accuracies, all approximately $0.4 \mathrm{~m}$ in displacement error (Dejong 1994; Dymond et al. 1992). The pixel value represents the brightness detected at various bands of the spectrum from 0 to 255. Since LULCC detection methods are developed into indices, no investigation of principal components analysis or edge detection was performed during this research.

Post processing of the images In this research, two methods were used to retrieve class boundary, namely, supervised classification and indices. By comparing the results derived from these two methods, the more precise one was confirmed as the class boundary. The three indices covered in this study were tested for vegetation changes (normalized difference vegetation index (NDVI)), extent of sand movement (CI), and determination of the type of topsoil grain size index (GSI), which were calculated respectively on the basis of the equations provided below.

- NDVI: The most common form of vegetation index is the normalized difference vegetation index or NDVI (Tucker 1979; Purevdorj et al. 1998). The NDVI is basically the difference between the red and near

Table 1 Some physical and chemical properties of soil type and their average value in the study area

\begin{tabular}{|c|c|c|c|c|c|c|c|}
\hline \multirow[t]{2}{*}{ Physical and chemical } & \multicolumn{7}{|c|}{ County name (ID)/area $\left(\mathrm{km}^{2}\right)$} \\
\hline & $\begin{array}{l}\text { Khaseeb } \\
(2) / 1,152\end{array}$ & $\begin{array}{l}\text { Midaina } \\
\text { (7)/989 }\end{array}$ & $\begin{array}{l}\text { Qurna } \\
(4) / 2,612\end{array}$ & $\begin{array}{l}\text { Zubair } \\
(6) / 11,618\end{array}$ & $\begin{array}{l}\text { Basrah } \\
(5) / 1,085\end{array}$ & $\begin{array}{l}\text { Fao } \\
\text { (1)/98 }\end{array}$ & $\begin{array}{l}\text { Shatt Al-A } \\
\text { (3)/1,516 }\end{array}$ \\
\hline Sand $\left(\mathrm{g} \mathrm{kg}^{-1}\right)$ & 245.0 & 133.1 & 240.0 & 930.9 & 255.4 & 123.0 & 161.1 \\
\hline Silt $\left(\mathrm{g} \mathrm{kg}^{-1}\right)$ & 483.6 & 394.4 & 489.6 & 10.2 & 463.5 & 486.6 & 541.2 \\
\hline Clay $\left(\mathrm{g} \mathrm{kg}^{-1}\right)$ & 271.4 & 472.5 & 270.4 & 40.8 & 281.1 & 390.4 & 297.7 \\
\hline Texture & Silty loam & Silty clay & Silty loam & Sandy & Silty loam & Silty clay & Silty loam \\
\hline \multicolumn{8}{|l|}{ Aggregate size (mm) } \\
\hline$>0.50 \%$ & 60.60 & 61.5 & 60.60 & 0.20 & 62.40 & 69.5 & 64.75 \\
\hline $0.5-0.25 \%$ & 10.30 & 9.45 & 10.30 & 8.02 & 8.40 & 5.45 & 6.44 \\
\hline $0.25-0.10 \%$ & 8.25 & 7.28 & 8.25 & 61.23 & 7.35 & 4.28 & 7.11 \\
\hline$<0.10 \%$ & 2.29 & 3.16 & 2.29 & 21.58 & 3.29 & 2.16 & 3.15 \\
\hline Grain mean diameter (mm) & 0.18 & 0.17 & 0.20 & 0.28 & 0.22 & 0.21 & 0.19 \\
\hline Bulk density $\left(\mathrm{g} \mathrm{cm}^{-3}\right)$ & 1.21 & 1.23 & 1.22 & 1.68 & 1.41 & 1.23 & 1.25 \\
\hline $\mathrm{pH}$ & 7.87 & 7.95 & 7.82 & 7.84 & 7.85 & 8.90 & 7.80 \\
\hline O.M $\left(\mathrm{g} \mathrm{kg}^{-1}\right)$ & 3.70 & 3.10 & 3.75 & 0.19 & 2.60 & 3.20 & 3.73 \\
\hline $\mathrm{EC} \mathrm{dsm}{ }^{-1}$ & 4.50 & 4.30 & 3.90 & 3.80 & 4.80 & 5.60 & 4.40 \\
\hline $\mathrm{CaCO}_{3}\left(\mathrm{~g} \mathrm{~kg}^{-1}\right)$ & 120.2 & 130.5 & 118.9 & 169.5 & 118.9 & 125.5 & 124.1 \\
\hline Groundwater $(\mathrm{cm})$ & $5-20$ & $2-15$ & $2-15$ & $20-50$ & $10-30$ & $2-15$ & $3-20$ \\
\hline
\end{tabular}


infrared band combination divided by the sum of the red and near infrared band combination or:

$\mathrm{NDVI}=(\mathrm{NIR}-R) /(\mathrm{NIR}+R)$

where $R$ and NIR are the red and near infrared bands.

- Crust index: In order to study a practicable indicator (fine sand content in topsoil) for monitoring the change of surface soil using remote sensing, soil index covered in this study, the CI, was tested for topsoil cover change.

The CI algorithm was run and a new dataset was generated. A spectral CI has been developed, based on the normalized difference between the red and the blue spectral values. Applying the index to a sand soil environment, it has been shown that the CI can be used to detect and to map, from remote sensing imagery, different lithologic/morphologic units such as active crusted sand areas, which are expressed in the topography. As a mapping tool, the CI image is much more sensitive to ground features than the original image (Karnieli 1997). The algorithm used is shown below:

$$
C I=1-(R-B) /(R+B)
$$

where $R$ and $B$ are the red and blue bands.

The distribution of soil crust is an important information for vegetation degradation and climate change studies. They are also highly valuable information tools for developing agricultural regions and/or infrastructures in location studies since soil crusts contribute to soil stability, soil build-up, and soil fertility (Karnieli 1997). The application of the proposed CI can be performed with imagery acquired by any sensor which contains the blue band (Karniel and Sarafis 1996). Currently, the most common data sources are color Landsat TM and Landsat ETM images as demonstrated in this research.

- Topsoil GSI: Topsoil GSI was developed based on the field survey of soil surface spectral reflectance and laboratory analyses of soil grain composition (Xiao et al. 2006). The GSI found has close correlation to the fine sand or clay-silt-sized grain content of the topsoil in sparsely vegetated arid land of Inner Mongolia, China. High GSI value corresponds to the area with high content of fine sand in topsoil or low content of clay-silt grains. The GSI can be simply calculated by

$$
\mathrm{GSI}=(R-B) /(R+B+G)
$$

where $R, B$, and $G$ are the red, blue, and green bands of the remote sensing data. GSI value is close to 0 in the vegetated area, and for water body, it is of negative value.
- Classification and class boundary: Unsupervised and supervised methods of classification were tested to delineate land use/land cover (LULC) areas. Because the assemblages are mixed in the class to be mapped, they will generally be referred to as class boundary. Supervised methods proved superior and are covered below. Density maps were created by correlating several test LULC indices to ground data from published papers about the location area. Class boundary properties can be delineated on an image to gather the spectral response for similar areas on the rest of the image. By gaining prior knowledge of an area on the image to be classified, response across all bands was matched using supervised methods to produce desirable output classes.

\section{Environmentally sensitive areas}

The identification of sensitive areas is based on the hypotheses of the MEDALUS project model (Kosmas et al. 1999). The model applies a geometrical average of some quality indices in order to provide sensitivity diagnosis. It assumes that each index has only a limited capacity to influence the final value of ESAs index, and only when several parameters have a high score, an area can be assigned to high sensitivity class. The following three quality indices were computed: SQI, VQI, and CQI. The methodology is based on the classification of each quality index obtained as geometric mean of available environmental and anthropogenic parameters. The available parameters are quantified in relation to their influence on the desertification process assigning score to each. The scores assigned to different parameters range between 1 (best value) and 2 (worst value). The final overall (ESAs) index is obtained as a geometrical average of the quality indices (Basso et al. 2000). Figure 2 demonstrates the main flow chart of concepts and studied steps performed in the current study. The main input data for calculating these indices include a mosaic of Landsat TM and ETM images, geologic map of the study location, and climatic data derived from the Ministry of Agriculture. An image processing system (i.e., ERDAS IMAGINE 9.2) and a GIS system (i.e., ArcGIS 9.3) were the main tools in indices computations and ESAs mapping.

- Mapping SQI: Soil is the dominant factor of the terrestrial ecosystems in the arid and semi-arid and dry zones, particularly through its effect on biomass production. Soil quality indicators for mapping ESAs can be related to water availability and erosion resistance (Basso et al. 1998). A number of three soil parameters were considered in the current investigation 
Table 2 Classes and assigned weighting index for parent material, soil texture, and soil depth

\footnotetext{
${ }^{\mathrm{a}}$ In case of deep Aeolian deposits over a rocky parent material, the Aeolian sediments are considered as parent material

${ }^{\mathrm{b}}$ Areas dominated by wind erosion
}

\begin{tabular}{|c|c|c|}
\hline & Description & Score \\
\hline \multicolumn{3}{|l|}{ Parent material classes ${ }^{\mathrm{a}}$} \\
\hline $\begin{array}{l}\text { Coherent: limestone, dolomite, non-friable sandstone, } \\
\text { hard limestone layer }\end{array}$ & Good & 1.0 \\
\hline $\begin{array}{l}\text { Moderately coherent: marine limestone, } \\
\text { friable sandstone }\end{array}$ & Moderate & 1.5 \\
\hline $\begin{array}{l}\text { Soft to friable: calcareous clay, clay, sandy formation, } \\
\text { alluvium and colluviums } \\
\text { Texture classes }\end{array}$ & Poor & 2.0 \\
\hline Not very light to average & Loamy sand, sandy loam, balanced ${ }^{\mathrm{b}}$ & 1.0 \\
\hline Fine to average & Loamy clay, clayey sand, sandy clay ${ }^{\mathrm{b}}$ & 1.7 \\
\hline Fine & Clayey, clay loam ${ }^{\mathrm{b}}$ & 2.0 \\
\hline Coarse & Sandy to very sandy ${ }^{\mathrm{b}}$ & 2.0 \\
\hline \multicolumn{3}{|l|}{ Soil depth classes } \\
\hline Very deep & Soil thickness is more than $1 \mathrm{~m}$ & 1.0 \\
\hline Moderately deep & Soil thickness ranges from $<1$ to $0.5 \mathrm{~m}$ & 1.3 \\
\hline Not deep & $\begin{array}{l}\text { Soil thickness ranges from } \\
<0.5 \text { to } 0.25 \mathrm{~m}\end{array}$ & 1.7 \\
\hline Very thin & Soil thickness $0.15 \mathrm{~m}$ & 2.0 \\
\hline
\end{tabular}

(i.e., parent material, soil texture, and soil depth). Weighting factors were assigned to each category of the considered parameters, on the basis of Basso et al. (2000), which were adapted from the MEDALUS project methodology (Kosmas et al. 1999). Table 2 demonstrates the assigned indices for different categories of each parameter. The SQI was classified according to categories shown in Table 3 and calculated on the basis of the following equation:

$\mathrm{SQI}=\left(I_{\mathrm{p}} \times I_{\mathrm{t}} \times I_{\mathrm{d}}\right)^{1 / 3}$

where $I_{\mathrm{p}}$ is the index of the parent material, $I_{\mathrm{t}}$ the index of soil texture, and $I_{\mathrm{d}}$ the index of soil depth.

- Mapping VQI: Vegetation quality according to Basso et al. (2000) is assessed in terms of three aspects, i.e., erosion protection to the soils, drought resistance, and plant cover. The TM and ETM satellite images mosaic covering the study location is the main material used to map vegetation and plant cover classes. Adapted rating values for erosion protection, drought resistance, and vegetal cover classes were adapted based on the study of Basso et al. (2000) as shown in Table 4. Vegetation quality index was classified on the basis of the ranges indicated in Table 5 and calculated according the following equation:

$\mathrm{VQI}=\left(I_{\mathrm{Ep}} \times I_{\mathrm{Dr}} \times I_{\mathrm{Vc}}\right)^{1 / 3}$

where $I_{\mathrm{Ep}}$ is the index of erosion protection, $I_{\mathrm{Dr}}$ the index of drought resistance, and $I_{\mathrm{Vc}}$ the index of vegetation cover. Ranking of different elements is based upon the magnitude of the fundamental role of vegetation in erosion protection, drought resistance, and soil capacity protection. The perennial cultivation provides a very high capacity to reduce the kinetic energy caused by the impact of the driving forces of soil erosion. Furthermore, the plant root system increases the stability of the soil; thus, a value of 1 was assigned to rank each of $I_{\mathrm{Ep}}, I_{\mathrm{Dr}}$, and $I_{\mathrm{Vc}}$. Gradual relative lower capacity is provided by other vegetation classes (e.g., halophytes, orchards, desert vegetation, etc.); thus, relatively higher values are assigned for different sensitivity indices.

- Mapping CQI: The aim of the CQI in the current investigation is to assess the availability of water to vegetation. Climatic quality is assessed by using parameters that influence water availability to plants such as the amount of rainfall, air temperature, and aridity, as well as climate hazards, which might inhibit plant growth (Thornes 1995). Table 6 reveals the classification categories of climatic quality index according to Kosmas et al. (1999). The climate quality index is evaluated through the aridity index, using the methodology developed by the Applied Meteorology Foundation (Basso et al. 2000) in accordance with the formula provided below. In the current study, rainfall and evapotranspiration data on a meteorological

Table 3 Classification of soil quality index (SQI)

\begin{tabular}{lll}
\hline Class & Description & Range \\
\hline 1 & High quality & $<1.13$ \\
2 & Moderate quality & 1.13 to 1.45 \\
3 & Low quality & $>1.46$ \\
\hline
\end{tabular}


Table 4 Classes and assigned weighting index for different vegetation parameters

\begin{tabular}{llccc}
\hline Class & Description & $I_{\mathrm{Ep}}$ & $I_{\mathrm{Dr}}$ & $I_{\mathrm{Vc}}$ \\
\hline 1 & Perennial cultivation & 1.0 & 1.0 & 1.0 \\
2 & Halophytes & 1.3 & 1.0 & 1.3 \\
3 & Temporal and orchards, mixed with crop land & 1.6 & 1.3 & 1.7 \\
4 & Desert vegetation $<40 \%$ & 2.0 & 1.6 & 1.0 \\
5 & Desert vegetation $>40 \%$ & 2.0 & 1.0 & 1.0 \\
\hline
\end{tabular}

stations, published in the monthly weather report (meteorological stations), were used to calculate the CQI as follows:

$\mathrm{CQI}=P / \mathrm{PET}$

where $P$ is the average annual precipitation and PET is the average annual potential evapotanspiration.

- ESAs to desertification: The ArcGIS software was used to map ESAs to desertification (Kosmas et al 1999) by integrating all data concerning soil, vegetation, climate, and extent of sand movement. Different quality indices were calculated and displayed as GIS ready maps from which class areas were deduced. DSI was classified on the basis of the ranges indicated in Table 7 and calculated in the polygonal attribute tables linked with the geographic coverage according to the following equation:

$\mathrm{DSI}=(\mathrm{SQI} * \mathrm{VQI} * \mathrm{CQI} * \mathrm{CL})^{1 / 4}$

where SQI is the soil quality index, VQI the vegetation index, CQI the climatic index, and CL the crust index.

\section{Results and discussion}

Sand movement severity

ERDAS Imagine and ESRI ArcGIS were used to quantify the area of the five LULC classes from the 1990 and 2003 classification maps. The software was also able to quantify the amount and type of change that occurred in each of the LULC classes over the 13-year study period. These

Table 5 Classification of vegetation quality index (VQI)

\begin{tabular}{lll}
\hline Class & Description & Range \\
\hline 1 & Good & $<1.2$ \\
2 & Average & 1.2 to 1.4 \\
3 & Weak & 1.4 to 1.6 \\
4 & Very weak & $>1.6$ \\
\hline
\end{tabular}

Table 6 Classification of climatic quality index (CQI)

\begin{tabular}{llll}
\hline Class number & Climatic zone & P/PET & CQI \\
\hline 1 & Hyper-arid & $<0.05$ & 2.0 \\
2 & Arid & $0.05-0.20$ & 1.75 \\
3 & Semi-arid & $0.20-0.50$ & 1.50 \\
4 & Dry sub-humid & $0.50-0.65$ & 1.25 \\
5 & Humid & $>0.65$ & 1.0 \\
\hline
\end{tabular}

numbers were used to create Tables 8 and 9. Table 8 quantifies the amount of land contained in each LULC class, the percentage of the study area encompassed by the LULC class, and the amount of growth of each of the LULC classes from 1990 to 2003. It can be seen from the study provided by the ERDAS software that the overall accuracy of classification of 1990 and 2003 reached $97.89 \%$ and $95.93 \%$, respectively. Table 9 shows and quantifies the transition of one LULC class into another LULC class from 1990 to 2003. For example, the table shows that $514.9 \mathrm{~km}^{2}$ of land that had been classified as vegetation land in 1990 was classified as sand land in 2003, and $228.9 \mathrm{~km}^{2}$ of land that had been classified as water bodies in 1990 was classified as urban or built up and barren lands in 2003 . This can be used to determine the extent of the changes taking place in the LULC over time.

Using Tables 8 and 9 together, significant changes in the LULC can be recognized and the type of LULC conversion taking place can be identified. From 1990 to 2003, a relatively dramatic increase in sand lands was seen. The areas that contributed the most to this change were vegetation land. This may suggest logging and development. During the same time span, urban areas also increased in size. The majority of this change came from the development of vegetation land into an urban class. A decrease of $228.9 \mathrm{~km}^{2}$ in size was seen in marshes. Some of the marshes were converted to unused land, while some of them were converted to urban. Finally, a decrease in size was seen in vegetation areas. The largest portion was converted to sand land, with another portion converted to barren, and a significant portion was developed into urban areas.

Table 7 Ranges and classes of desertification sensitivity index (DSI)

\begin{tabular}{lll}
\hline Class & SDSI & Description \\
\hline 1 & SDSI $<1.2$ & Very low sensitive areas to desertification \\
2 & $1.2<$ SDSI $<1.3$ & Low sensitive areas to desertification \\
3 & $1.3<$ SDSI $<1.4$ & Medium sensitive areas to desertification \\
4 & $1.4>$ SDSI $<1.6$ & Sensitive areas to desertification \\
5 & SDSI $>1.6$ & Very sensitive areas to desertification \\
\hline
\end{tabular}


Table 8 Calculated LULC class totals monitored and drifting sand increasing rates from satellite image for the study area during the period from 1990 to 2003

\begin{tabular}{|c|c|c|c|c|c|c|}
\hline \multicolumn{7}{|c|}{ Supervised classification method } \\
\hline LULC classes & \multicolumn{4}{|c|}{ Area $\left(\mathrm{km}^{2}\right)$} & Amount of change $\left(\mathrm{km}^{2}\right)$ & Percentage growth \\
\hline Vegetation land & $5,110.8$ & 26.8 & $4,595.9$ & 24.1 & -514.9 & $-10.1^{\mathrm{a}}$ \\
\hline Sand land & $4,119.1$ & 21.6 & $4,557.7$ & 23.9 & 438.6 & 10.6 \\
\hline Urban area & $3,299.1$ & 17.3 & $3,794.9$ & 19.9 & 495.8 & 15.1 \\
\hline Bare land & $3,146.5$ & 16.5 & $3,356.3$ & 17.6 & 209.8 & 6.6 \\
\hline Water bodies & $3,184.7$ & 16.7 & $2,955.9$ & 15.5 & -228.9 & -7.2 \\
\hline \multicolumn{7}{|c|}{ Crust index (CI) method } \\
\hline Total area $\left(\mathrm{km}^{2}\right)$ & \multicolumn{2}{|c|}{ Drifting sand 1990} & \multicolumn{2}{|c|}{ Drifting sand 2003} & $\begin{array}{l}\text { Drifting sand } 1990 \sim 2003 \\
\left(\mathrm{~km}^{2}\right)\end{array}$ & $\begin{array}{l}\text { Drifting sand rate } \\
\left(\mathrm{km}^{2} \text { year }\right.\end{array}$ \\
\hline 19,070 & 4118.3 & 21.5 & 4558.1 & 23.9 & 439.8 & $33.8^{\mathrm{b}}$ \\
\hline
\end{tabular}

${ }^{a}$ Percentage growth $=$ amount of change $\left(\mathrm{km}^{2}\right) /$ area $\left(\mathrm{km}^{2}\right) 1990 \times 100$

${ }^{\mathrm{b}}$ Drifting sand rate $=$ drifting sand $(1990 \sim 2003) / 100$

Comparison of land use/cover and the drifting sand coverage images, produced by applying supervisor classification and crust index algorithms (Fig. 3a, b and Table 8), reveals that the extent of degraded land within the study area has expanded from the northwest towards the southeast, while the overall sandy desertification has worsened. This has been confirmed by field investigation. The drifting sand coverage expansion rate of $33.8 \mathrm{~km}^{2}$ year ${ }^{-1}$ was in the study locations. Evidently, the rate of sandy desertification has accelerated during the study period within the study region. Covering $19.9 \%$ of the area, mobile sand dunes with a height ranging from 3.5 to $5.5 \mathrm{~m}$ are designated as class 4 of DSI. Their extent is under the influence of drifting sand and wind erosion, with vegetation cover of $<20 \%$. The majority of land encrusted with sand movement is unsuitable for productive use. Only a small proportion of inter-dune areas can be used for grazing. The results indicate that the vegetation cover in the study location declined from $19.5 \%$ in 1990 to $12.7 \%$ in 2003 , which is designated as class 4 of DSI (Table 13).

High DSI class 5 has a high degree of severity caused mainly by drifting sand that accounts for $28.1 \%$ in areal proportion. Sand dunes inside this category are semistabilized and have a wave-like appearance. Mobile sand dunes are $2.5-5.5 \mathrm{~m}$ high while vegetation cover is only $10-15 \%$. A less than a quarter of the study area $\left(4,767.5 \mathrm{~km}^{2}\right)$ is subject to the impact of drifting sand and/ or wind erosion, while vegetation covers less than $11 \%$. There was $21.5 \%$ of the total study area covered by the drifting sand in the year 1990, while the coverage percentage rose to $23.9 \%$ in the year 2003 , accompanied by a decrease in vegetation cover percentage of the area from $26.8 \%$ to $24.1 \%$ in the years 1990 and 2003, respectively.

Soil quality index

The SQI was evaluated depending upon soil texture class, soil depth (centimeter), and parent material. Figure 4 and Table 10 represent the layer of soil quality index of the study area. The results indicate that the areas of moderate soil quality index (value $=1.2-1.4$ ) represent $20.8 \%$ of the total area (i.e., $3,966.5 \mathrm{~km}^{2}$ ), the areas of low soil quality index (value $=1.4-1.6$ ) represent $29.3 \%$ of the total area (i.e., $5,587.5 \mathrm{~km}^{2}$ ), and the areas of low soil quality index (value $>1.6$ ) represent $49.9 \%$ of the total area (i.e., $9,515.9 \mathrm{~km}^{2}$ ). The low soil quality dominates the areas characterized by sandy texture, shallow depth, and poor drainage.
Table 9 LULC cover transition matrix $\left(\mathrm{km}^{2}\right)$

\begin{tabular}{llllllll}
\hline \multicolumn{1}{l}{1990} & \multicolumn{7}{c}{} \\
\cline { 2 - 7 } & Transition & Vegetation & Sand & Urban & Barren & Water & 2003 totals \\
\hline 2003 & Vegetation & $3,107.2$ & 769.1 & 318.8 & 270.2 & 130.5 & $4,595.9$ \\
& Sand land & 972.2 & $2,869.2$ & 349.6 & 258.5 & 108.1 & $4,557.7$ \\
& Urban area & 489.2 & 116.1 & $2,302.5$ & 567.3 & 319.4 & $3,794.9$ \\
Barren & 440.4 & 266.3 & 221.1 & $1,814.4$ & 213.9 & $3,356.3$ \\
Water & 101.6 & 98.3 & 107.1 & 236.2 & $2,412.6$ & $2,955.9$ \\
& 1990 totals & $5,110.8$ & $4,119.1$ & $3,299.1$ & $3,146.5$ & $3,184.7$ & \\
\hline
\end{tabular}



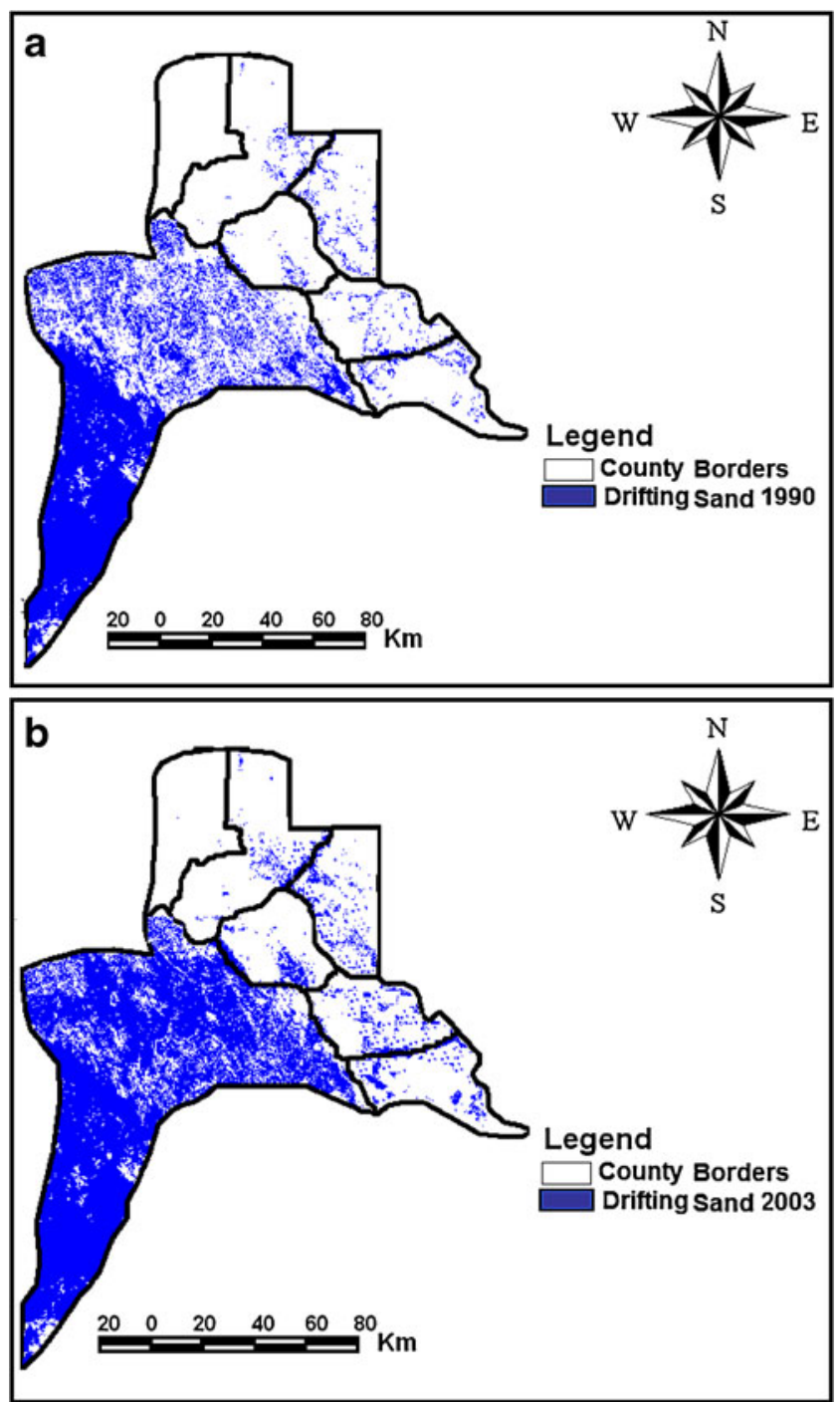

Fig. 3 a Soil crust index layer performed on the study area for the year 1990. b Soil crust index layer performed on the study area for the year 2003

Vegetation quality index

Vegetation plays an important role in mitigating the effects of desertification and degradation phenomena. The plant cover (percentage), erosion protection, and drought resistance parameters were used for assessing the VQI. Figure 5 and Table 11 represent the layer of vegetation quality index of the area. The data indicate that the areas of good vegetation quality (value $<$ 1.2) dominate the southeastern parts of the study location, representing $9.5 \%$ of the total area (i.e., $1,811.6 \mathrm{~km}^{2}$ ), and the average vegetation quality index (value $1.2-1.4$ ) dominates the southern and northwestern parts of the study location, representing $19.9 \%$ of the total area (i.e., $3,794.9 \mathrm{~km}^{2}$ ). The weak (value 1.4-1.6) and the very weak vegetation indices (value $>1.6$ ) dominate the rest of the study location representing $29.7 \%$ and $40.9 \%$ of the total area, respectively. The weak vegetation index is due to the low density of plant cover.

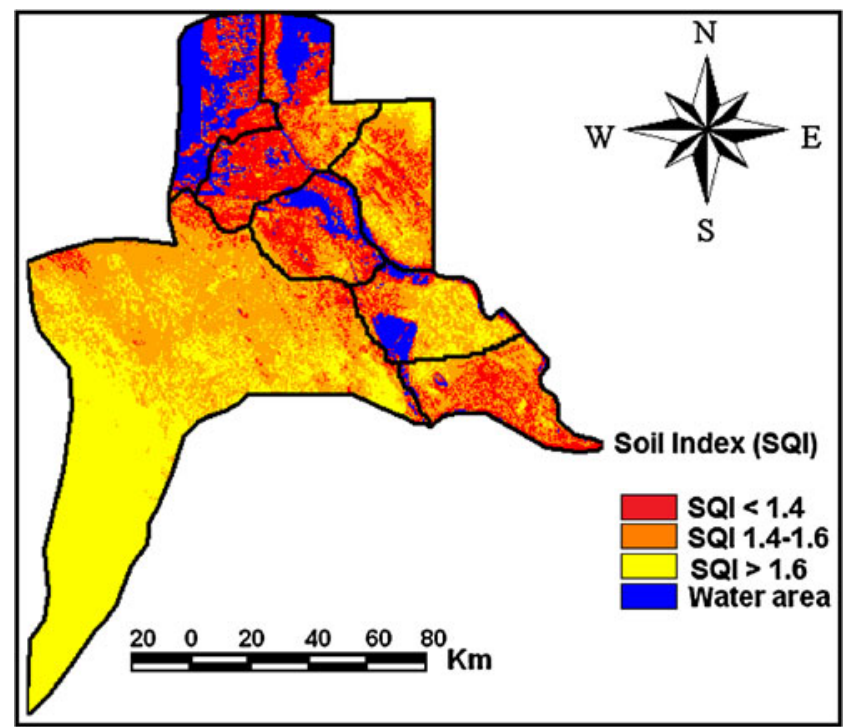

Fig. 4 Soil quality index $(S Q I)$ layer of Basrah Province

Climate quality index

Climatic data (i.e., rainfall and evapotranspiration) interpolation resulted in obtaining values for both parameters. The climatic sensitivity index was calculated and stored in a GIS ready map (Fig. 6). Most rain-fed areas are located in the marshlands region and do not exceed $100 \mathrm{~mm}$ annually. The average annual rainfall drops down to almost 50$80 \mathrm{~mm}$, at less than 100-200 km distance west of the Shatt Al-Arab coast. The average annual potential evapotranspiration is relatively high in the whole study location; however, it increases northwestwards. It is clear that the area is dominated by semi-arid (value $=1.5-1.6$ ) and arid (value 1.7-1.8) CQI. Table 12 shows the areas of climatic quality index classes. The arid climatic conditions characterize $79.6 \%$ of the whole study location (i.e., $15,179.7 \mathrm{~km}^{2}$ ), while $20.4 \%$ is characterized by semi-arid climatic conditions (i.e., $3,890.3 \mathrm{~km}^{2}$ ).

Arid environmental sensitivity to desertification assessment

The four previous indices were driven together for the assessment of the arid environmentally sensitive areas to

Table 10 Areas of different categories of soil quality index (SQI) classes

\begin{tabular}{llcc}
\hline Class & Score & Area $\left(\mathrm{km}^{2}\right)$ & Percentage \\
\hline Very low quality & SQI $>1.6$ & $9,515.9$ & 49.9 \\
Low quality & $1.4-1.6$ & $5,587.5$ & 29.3 \\
Moderate quality & $1.2-1.4$ & $3,966.5$ & 20.8 \\
Total & - & 19,070 & 100 \\
\hline
\end{tabular}




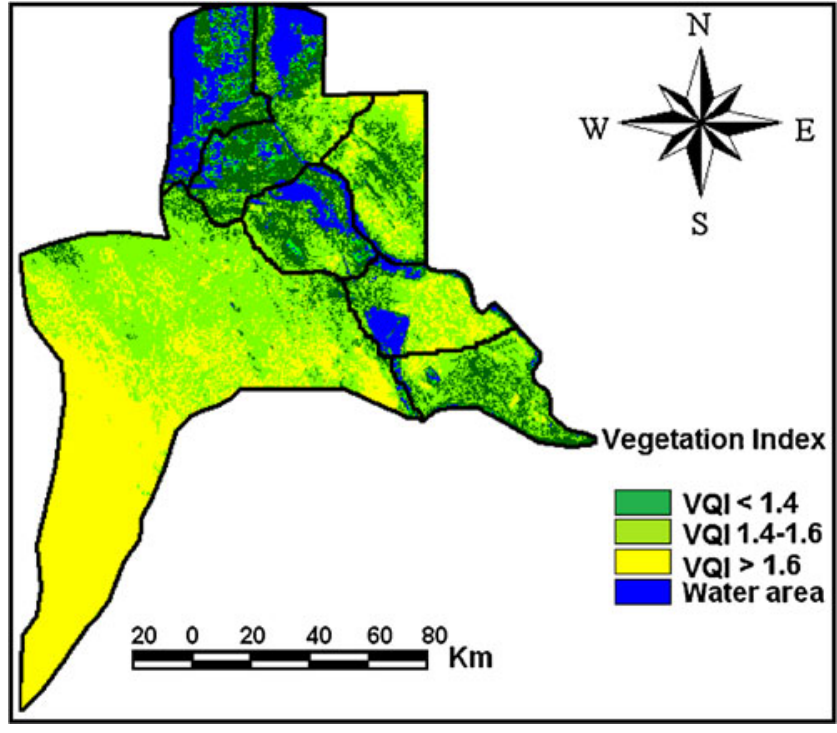

Fig. 5 Vegetation quality index $(V Q I)$ layer of Basrah Province

desertification, on the basis of the calculated DSI. Figure 7 and Table 13 show the distribution of ESAs in the study location, and it is clear that the highly sensitive areas to desertification in Basrah Province are found in the western parts, where soil quality, climatic quality, and management quality are low. These areas represent $61.9 \%$ of the study location area (i.e., $11,804.3 \mathrm{~km}^{2}$ ). The areas of moderate sensitivity for sandy desertification are exhibited by the rest of the southern parts of the study location, representing $18.9 \%$ of the total area (i.e., $3,604.2 \mathrm{~km}^{2}$ ). The northern parts of the study location are characterized by a very low and low sensitivity for sandy desertification, representing $10.7 \%$ and $8.5 \%$ of the total area, respectively. The low sensitivity for sandy desertification is due to the good vegetation cover and soil quality. The results of this study indicated that sandy desertification results from natural and anthropogenic factors. Overlay of DSI layers interpreted from multi-temporal remotely sensed materials in a GIS, in conjunction with field investigation, revealed that the spatial extent of sandy desertified land in the area has drastically expanded during the 13-year study period (1990-2003).

The result obtained by the ESAs method reveals that the study area comprises four sensitivity classes such as

Table 11 Areas of different vegetation quality index (VQI) classes

\begin{tabular}{llcc}
\hline Class & Score & Area $\left(\mathrm{km}^{2}\right)$ & Percentage \\
\hline Good & VQI $<1.2$ & $1,811.6$ & 9.5 \\
Average & $1.2-1.4$ & $3,794.9$ & 19.9 \\
Weak & $1.4-1.6$ & $5,663.8$ & 29.7 \\
Very weak & VQI $>1.6$ & $7,799.6$ & 40.9 \\
Total $\left(\mathrm{km}^{2}\right)$ & - & 19,070 & 100 \\
\hline
\end{tabular}

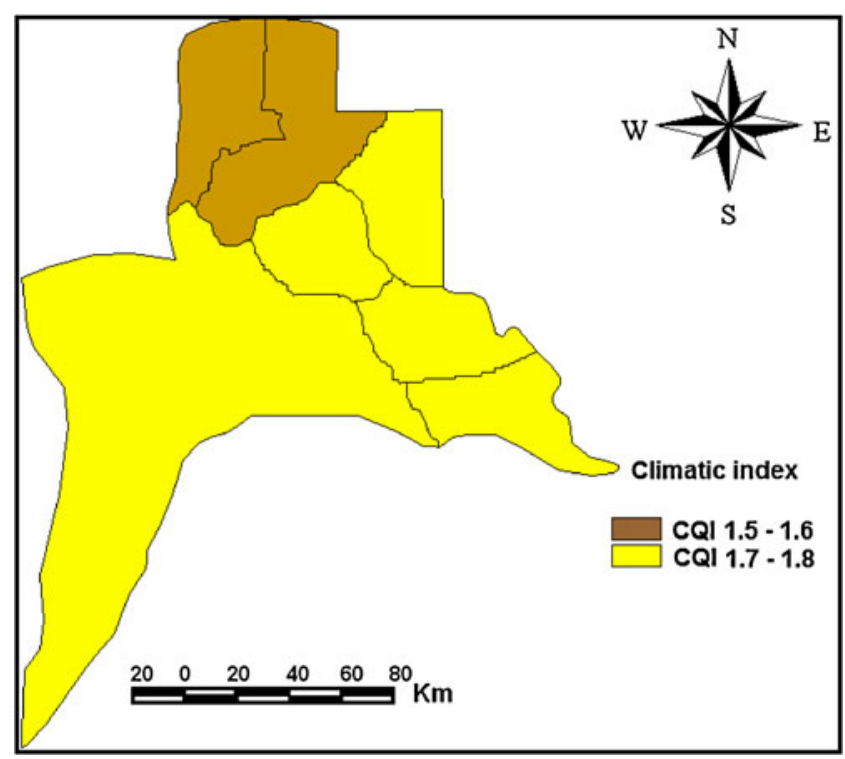

Fig. 6 Climatic quality index $(C Q I)$ layer of Basrah Province based on meteorological data

critical, fragile, and potential to desertification, and low affected. It is seen that most of the area is under danger of fragile to critical condition which needs urgent remedies (Fig. 7 and Table 13). Also, the average weight of desertification indices shows that four desertification factors, for instance, scale of soil, climate, extent of sand movement, and percentage of plant covering with values of $26.8 \%$ in 1990 to $24.1 \%$ in 2003 , have the most effect in desertification (Table 8). Another good feature of this study within GIS was to evaluate the relationship of desertification sensitivity with type of CI present in the area. As shown in Table 8, the most critical class has more of sand soil than clay soil, so it is reverse for higher sensitive areas.

DSI in the study area was assessed through consideration of both natural (vegetative index, soil index, climatic index, drifting sand) and anthropogenic (land use/cover change) factors in the study. It was found that most of the study locations were highly sandy-desertified. The overall sensitivity of sandy desertification has worsened during the study period with degraded areas accounting for $61.9 \%$ of the total area in 2003. There is a clear trend in the spatial distribution of the sandy desertification direction within the study area, which goes from the northwest toward the southeast. The risk has risen considerably, on average, by $40 \%$ for all western parts of the study location between

Table 12 Areas of different climatic quality index (CQI) classes

\begin{tabular}{lllcc}
\hline Class & P/PET & Score & Area $\left(\mathrm{km}^{2}\right)$ & Percentage \\
\hline Arid & $0.05-0.20$ & $1.7-1.8$ & $15,179.7$ & 79.6 \\
Semi-arid & $0.20-0.50$ & $1.5-1.6$ & $3,890.3$ & 20.4 \\
Total & & - & 19,070 & 100 \\
\hline
\end{tabular}




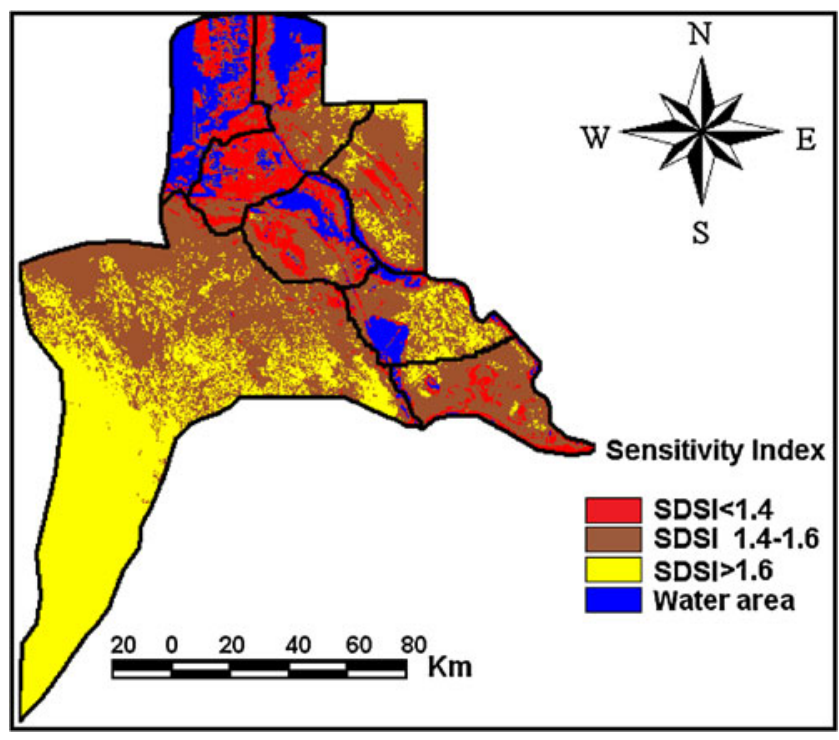

Fig. 7 Environmentally sensitive areas (ESAs) for sandy desertification in Basrah Province

1990 and 2003. In particular, the risk has increased considerably for those areas not previously considered highly vulnerable to degradation. Consequently, the disparity of sandy desertification hazard among the study locations has shrunk as all of them are at a higher risk in 2003 than ever before. The accentuation of sandy desertification is attributed to conflicts among human interest, increasing population pressure, limited land resource, and fragile ecosystems. Inappropriate human activities such as excessive exploitation of natural resources and mismanagement of land, to a certain extent, have contributed to the environmental destruction.

\section{Conclusion}

This study was conducted in order to detect sandy desertification during a 13-year period and quantify the landscape transformation condition using remote sensing and GIS technology based on ESAs to desertification. It was feasible and effective in selecting remote sensing data as the basic information sources and using the GIS software as the analysis processing tool, which allow the creation of thematic layers in a raster format. This data structure can provide the most comprehensive modeling for layers analysis for special purposes, i.e., assessing the sandy desertification sensitivity index and mapping the environmentally sensitive areas. From the above analyses, we can conclude that the findings in this study have profound implications on how to reduce the severity of sandy desertification risk in the study areas. As the cause of this problem is both natural and anthropogenic in origin, any measure must deal with the problems of rural economic development, especially the development of agriculture and animal husbandry. In accordance with Jabbar (2001), who indicated the importance of soil conditioners for the fixation of sand soil in Iraq, and Zhu and Wang (1993), who developed a model for rehabilitation of desertified land in which experimental demonstration was combined with popularization processes, we consider that successful solutions to the problem require a combination of mechanical, biological, ecological, engineering, and legislative measures. Mechanical measures, such as bundling and deployment of straw grid fences, clayey block barriers, cane branch barriers, and dry planting of Tamarix articulata cuttings in flat sandy areas, aim to stabilize mobile sand dunes, while biological measures aim to reduce wind velocity by erection of windbreaks (Jabbar et al. 2002; Jabbar 2003). Ecological measures include diversification of traditional farming activities including animal husbandry and forestry. A systematic approach would include the establishment of effective vegetation cover composed of forest belts, windbreak networks, and scattered patches of orchards and grassland. Engineering measures such as water conservancy projects or catchment development would aim to improve the conservation of rainwater for facilitating survival and growth of vegetation, thus stabilizing mobile dunes. The assessment of sandy desertification sensitivity is rather important to plan combating actions and to improve the employment of natural resources. The quantitative aspect of desertification sensitivity demonstrates a clearer image of the risk status; thus, reliable priority actions can be planned. Action measures are essential for intended sustainable agricultural projects in Basrah especially in the western parts which are susceptible to moderate or high desertification sensitivity.
Table 13 Occurrence of desertification sensitivity index (DSI)

\begin{tabular}{llcc}
\hline Class & Score & Area $\left(\mathrm{km}^{2}\right)$ & Percentage \\
\hline Non-affected or very low sensitive areas & $<1.2$ & $1,620.9$ & 8.5 \\
Low sensitive areas to desertification & $1.2-1.3$ & $2,040.5$ & 10.7 \\
Moderately sensitive areas & $1.3-1.4$ & $3,604.2$ & 18.9 \\
Sensitive areas to desertification & $1.4-1.6$ & $6,445.6$ & 33.8 \\
Very sensitive areas to desertification & $>1.6$ & $5,358.7$ & 28.1 \\
Total & - & 19,070 & 100 \\
\hline
\end{tabular}


Acknowledgments This work was funded by Al-Basrah University, Iraq and the 973 Program (grant no. 2006CB701300), China and supported by The Knowledge State Key Laboratory of Information Engineering in Surveying, Mapping and Remote Sensing (LIESMARS), Wuhan University.

Open Access This article is distributed under the terms of the Creative Commons Attribution Noncommercial License which permits any noncommercial use, distribution, and reproduction in any medium, provided the original author(s) and source are credited.

\section{References}

Abahussain AA, Abdu AS, Al-Zubari WKA, El-Din NA, AbdulRaheem M (2002) Desertification in the Arab region: analysis of current status and trends. J Arid Environ 51:521-545

Al Dousari AM, Misak R, Shahid S (2000) Soil compaction and sealing in Al-Salmi area, Western Kuwait. Land Degrad Dev 11:401-418

Basso F, Bellotti A, Bove E, Faretta S, Ferrara A, Mancino G, Pisante M, Quaranta G, Taberner M (1998) Degradation processes in the Agri Basin: evaluating environmental sensitivity to desertification at basin scale. Proceedings International Seminar on Indicator for Assessing Desertification in the Mediterranean Porto Torres, Italy 18-20 September. Supported by ANPA via Brancati 48-00144 Roma, pp 131-145.

Basso F, Bove E, Dumontet S, Ferrara A, Pisante M, Quaranta G, Taberner M (2000) Evaluating environmental sensitivity at the basin scale through the use of geographic information systems and remotely sensed data: an example covering the Agri Basin (southern Italy). Catena 40:19-35

Binns T (1990) Is desertification a myth? Geography 75:106-113

Black GR (1965) Bulk density. In: Black CA, Evans DD, White JL (eds) Methods of soil analysis. Part 1. Agronomy. Madison: American Society of Agronomy, 9, pp 379-390

Collado AD, Chuvieco E, Camarasa A (2002) Satellite remote sensing analysis to monitor desertification processes in the croprangeland boundary of Argentina. J Arid Environ 52:121-133

Dejong SM (1994) Derivation of vegetative variables from a Landsat TM image for modeling soil-erosion. Earth Surf Process Land 19 (2):165-178

Dymond JR, Stephens PR, Newsome PF, Wilke RH (1992) Percentage vegetation covers of a degrading rangeland from SPOT. Int $\mathrm{J}$ Remote Sens 13(11):1999-2007

Ferrara A, Bellotti A, Faretta S, Mancino G, Taberner M (1999) Identification and assessment of environmentally sensitive areas by remote sensing, MEDALUS III 2.6.2., OU Final Report. King's College, London, 2, pp 397-429

Jabbar MT (2001) Soil loss by wind erosion for three different textured soil treated with polyacrylamide and crude oil, Iraq. J China Univ Geosci 2:113-116

Jabbar MT (2003) Using remote sensing and GIS techniques to study soil degradation processes in North Shaanxi Province, China. J China Univ Geosci 4:356-362
Jabbar MT, Xiaoling C (2006) Land degradation assessment with the aid of geo-information techniques. J Earth Surf Processes Landf 31:777-784

Jabbar MT, Guangdao H, Jianguo C (2002) Study of sand dunes and their effect on desertification of cultivated lands in Shaanxi Province, China using remote sensing techniques. J China Univ Geosci 3:234-239

Karnieli A (1997) Development and implementation of spectral crust index over dune sands. Int J Remote Sens 18:1207-1220

Karniel K, SARAFIS V (1996) Reflectance spectrometry of Cyanobacteria within soil crusts - a diagnostic tool. Int J Remote Sens 8:1609-1615

Kassas M (1995) Desertification: a general review. J Arid Environ 30:115-128

Kosmas C, Ferrara A, Briasouli H and Imeson A (1999) Methodology for mapping environmentally sensitive areas (ESAs) to desertification. Mediterranean desertification and land use (MEDALUS), European Union 18882, pp 31-47. ISBN 92-828-6349-2

Koulouri M, Giourge C (2007) Land abandonment and slope gradient as key factors of soil erosion in Mediterranean terraced land. Catena 69:274-281

Nicholson SE, Tucker CJ, Ba MB (1998) Desertification, drought and surface vegetation: an example from the West African Sahel. Bull Am Meteorol Soc 79(5):815-829

Purevdorj TS, Tateishi R, Ishiyama T, Honda Y (1998) Relationships between percent vegetation cover and vegetation indices. Int $\mathrm{J}$ Remote Sens 19(18):3519-3535

Thomas DSG (1997) Science and the desertification debate. J Arid Environ 37:599-608

Thornes JB (1995) Mediterranean desertification and the vegetation cover. In: Fantechi R, Peter D, Balabanis P, Rubio JL (eds) EUR 15415 desertification in a European context: physical and socioeconomic aspects. Office for Official Publications of the European Communities, Brussels, pp 169-194

Tucker CJ (1979) Red and photographic infrared linear combinations for monitoring vegetation. Remote Sens Environ 8(2):127-150

UNEP (2001) The Mesopotamian marshlands: the demise of an ecosystem. Early Warning and Technical Assessment Report, UNEP/DEWA/TR.01-3. http://www.grid.unep.ch/activities/ sustainable/tigris/mesopotamia.pdf. Accessed May 2003

USDA (2004) Soil survey laboratory methods manual. Soil survey investigation report no. 42, version 4.0. US Gov. Print. Office, Washington

Vandekerckhove L, Poesen J, Oostwoud Wijdenes D, de Figueiredo T (1998) Topographical thresholds for ephemeral gully initiation in intensively cultivated areas of the Mediterranean. Catena 33:271292

World Meteorological Organization (WMO) (2005) Climate and land degradation, WMO No. 989, ISBN 92-63-10989-3.

Xiao J, Shen Y, Tateishi R, Bayer W (2006) Development of grain size index for monitoring desertification in arid land using remote sensing. Int J Remote Sens 27(12):2411-2422

Zha Y, Gao J (1997) Characteristics of desertification and its rehabilitation in China. J Arid Environ 37:419-432

Zhu Z, Wang T (1993) Trends in desertification and its rehabilitation in China. Desertif Control Bull 22:27-30 